\title{
Placental Transfusion for Asphyxiated Infants
}

\author{
Anup C. Katheria ${ }^{1 *}$, Wade D. Rich ${ }^{1}$, Sunita Bava ${ }^{2}$ and Satyan Lakshminrusimha ${ }^{3}$ \\ ${ }^{1}$ Sharp Mary Birch Hospital for Women \& Newborns, San Diego, CA, United States, ${ }^{2}$ Independent Researcher, San Diego, \\ CA, United States, ${ }^{3}$ Department of Pediatrics, University of California, Davis, Davis, CA, United States
}

The current recommendation for umbilical cord management of non-vigorous infants (limp, pale, and not breathing) who need resuscitation at birth is to immediately clamp the umbilical cord. This recommendation is due in part to insufficient evidence for delayed cord clamping (DCC) or umbilical cord milking (UCM). These methods may provide a neuroprotective mechanism that also facilitates cardiovascular transition for non-vigorous infants at birth.

Keywords: placental transfusion, cord milking, delayed cord clamping, newborn, asphyxia

\section{BACKGROUND}

An estimated one million newborns worldwide suffer from perinatal asphyxia which lead them to being at risk for developing hypoxic-ischemic encephalopathy (HIE) due to inadequate blood flow and oxygen delivery to the neonatal brain and other vital organs such as the heart and kidneys. The incidence of HIE is 1-3/1,000 term births in high-income countries but is 15-20 times greater in low to middle-income countries. The majority of infants with severe HIE and $30-50 \%$ infants with moderate HIE either die or develop significant disabilities. In addition, subtle cognitive deficits and alterations in daily life functioning are seen even in infants with mild HIE (1).

The need for resuscitation has been identified as marker for increased risk for HIE (2-5). Improvements in delivery room management could significantly affect long-term outcomes. Helping Babies Breathe, a resuscitation algorithm developed by the American Academy of Pediatrics, has reduced mortality by training providers to provide early resuscitation with ventilation but surviving infants are still at risk for neurodevelopmental impairment. Immediate clamping and resuscitation has been the standard of care, but this approach may be detrimental by limiting placental transfusion. Early resuscitation with positive pressure ventilation (PPV) may have benefits, but receiving additional blood through delayed cord clamping (DCC) may potentially increase intravascular volume and improve perfusion.

Following normal vaginal delivery, the newly born infant cries as the uterus contracts around the placenta. The combined effect of lung ventilation and uterine contraction promotes placental transfusion. Yao et al. demonstrated that blood flow continues until about $45 \mathrm{~s}$ after birth in the umbilical arteries while the umbilical vein remains patent until about $3 \mathrm{~min}$ of birth in healthy term infants (6). This results in a net transfer of blood volume from the placenta to the fetus during birth (7). However, infants at risk for asphyxia may be at risk for not receiving this transfusion at birth. Fetal blood volume loss to the placenta may occur when delivery is associated with shoulder dystocia or a tight nuchal cord $(7,8)$. In the presence of cord prolapse or nuchal cord, the infant as it traverses the tight birth canal, may compress the umbilical cord. In the umbilical cord, the muscular-walled, high-pressure arteries allow blood from the fetus to the placenta, while return flow from the placenta to the fetus in the thin-walled vein may be diminished or even occluded during cord compression (Figure 1). If the nuchal cord is extremely tight there may be complete occlusion of both umbilical arteries and vein in the cord. 
A
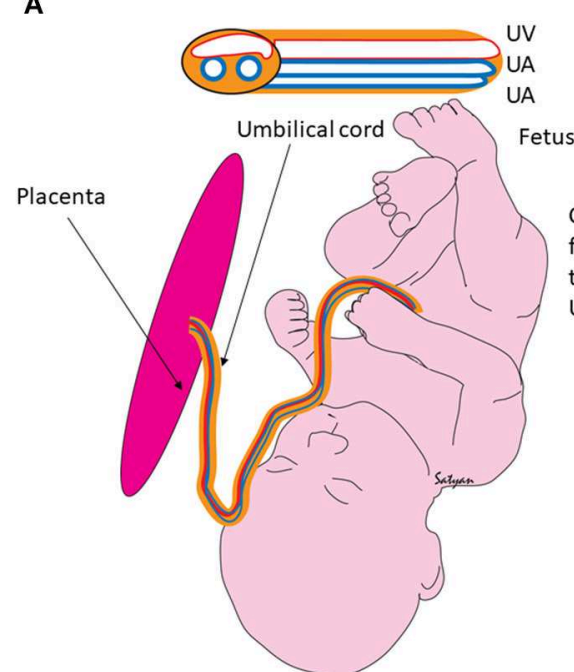

C
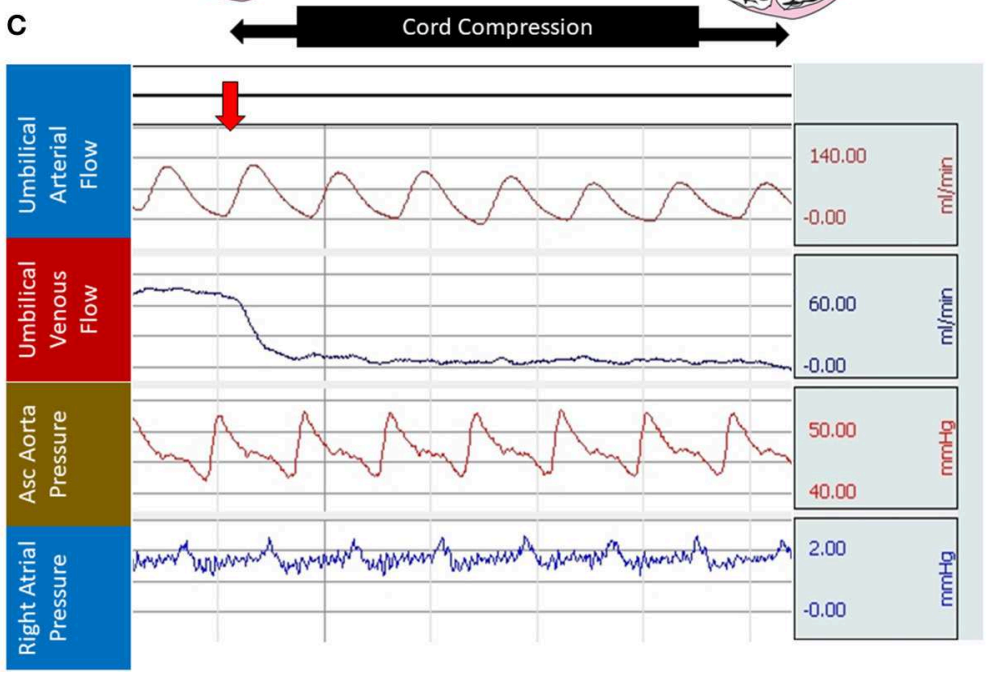

B

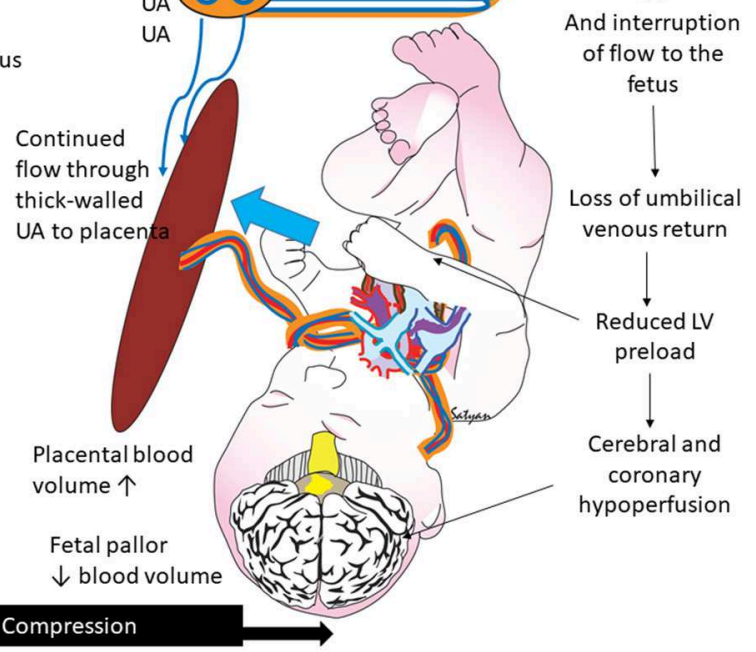

$(2)$

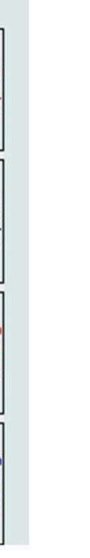

FIGURE 1 | Cord compression and hypovolemia: (A) normal fetus with thin walled umbilical vein (UV) transferring blood from the placenta to the fetus and two thick walled umbilical arteries (UA) bringing blood from the fetus to the placenta. (B) Cord compression initially occludes the thin-walled UV limiting umbilical venous flow to the fetus. The thick-walled UAs continue to maintain blood flow from the fetus to the placenta (blue arrow). This process leads to increased placental blood volume and reduced fetal blood volume. (C) Graph from a full-term fetus showing umbilical arterial flow (persists during cord compression), umbilical venous flow (abolished after cord compression), systemic blood pressure, and right atrial pressure. Selective loss of umbilical venous flow causes hypovolemia. Copyright Satyan Lakshminrusimha, MD.

Newborns in distress are more likely to be delivered by cesarean delivery (Figure 2). These infants are also less likely to get an adequate transfer of blood even with DCC. The intact contracting uterus is the largest driving force of a placental transfusion (up to $100 \mathrm{~mm} \mathrm{Hg}$ ). Aladangady et al. reported lower circulating red cell volume with DCC in neonates delivered by cesarean section compared to vaginal delivery (9). They also found that blood volume increased as duration of DCC was prolonged up to $60 \mathrm{~s}$ in infants with vaginal delivery, but not following cesarean delivery. Strauss et al. found cesarean section delivered newborns who received DCC for $60 \mathrm{~s}$ had decreased red cell volume compared to vaginal delivered infants (10).
McDonald et al. failed to show any difference in hemoglobin levels with a 30-s DCC among infants delivered by cesarean delivery (11).

The current recommendation for umbilical cord management of infants who are depressed and need resuscitation at birth is to immediately clamp the umbilical cord. This recommendation is due in part to insufficient evidence to support DCC or umbilical cord milking (UCM) in the presence of perinatal distress (12). However, these placental transfusion methods may facilitate cardiovascular transition and be neuroprotective in non-vigorous infants at birth. This additional blood provides an increased cardiac preload before the placenta is removed from the circulation and increases blood volume, which 


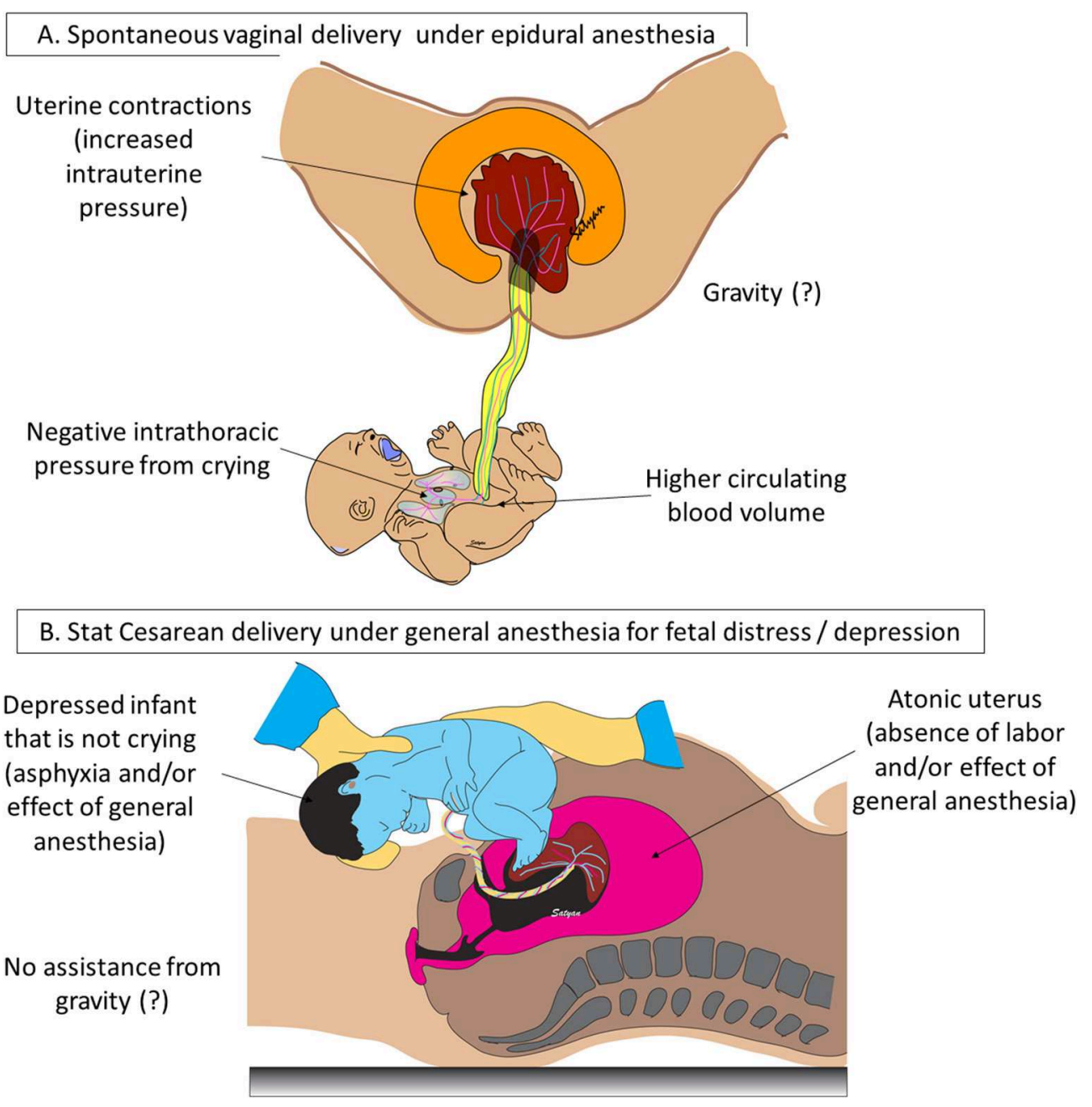

FIGURE 2 | Mode of delivery, anesthesia, and neonatal vigor influence placental transfusion: (A) following a spontaneous vaginal delivery without general anesthesia, uterine contractions generate high intrauterine pressure $(\sim 100 \mathrm{~mm} \mathrm{Hg})$. A baby held below the introitus may benefit from gravity to enhance placental transfusion although gravity is not an absolute requirement for transfer of blood to the newly born infant. Negative intrathoracic pressure induced by active crying in a vigorous neonate can assist placental transfusion. (B) Following stat cesarean section under general anesthesia for fetal distress or asphyxia, uterus is atonic, infant is depressed and may not be active and baby is held at the level of the abdomen. These factors can potentially reduce the volume of placental transfusion. Copyright Satyan Lakshminrusimha, MD.

will stabilize cardiac output and pulmonary and cerebral circulation, potentially improving further ischemia in an already compromised infant (13).

Compared to early cord clamping (ECC), both UCM and DCC have demonstrated improvements in systemic and brain perfusion, suggesting neuroprotective benefits $(14,15)$. DCC and/or UCM have been shown to improve heart rate, blood pressure, urine output and cerebral oxygenation, increase early hemoglobin levels, and prevent anemia in term and preterm infants without adverse effects or harm noted in any of the studies (15-24). The need for further research has been identified by the American Congress of Obstetricians \& Gynecologists, which states, "infants requiring resuscitation may benefit considerably from placental transfusion, but their need for immediate attention raises questions about whether they should undergo immediate or delayed umbilical cord clamping and whether UCM may offer a unique benefit" (25).

\section{HYPOVOLEMIA DURING ASPHYXIA}

When the cord is cut rapidly, the infant has no access to approximately $30 \mathrm{~mL} / \mathrm{kg}$ of blood-about 30 percent of the fetalplacental blood volume in a term neonate (26)-resulting in essential hypovolemia when the lungs are first aerated after ECC (Figure 3). Placental transfusion to the infant increases blood flow to the circulatory beds while the infant's various organs (lung, liver, kidney, etc.) assume the many functions maintained by the placenta during fetal life. Losing this additional blood volume due to ECC could increase inflammatory processes and 


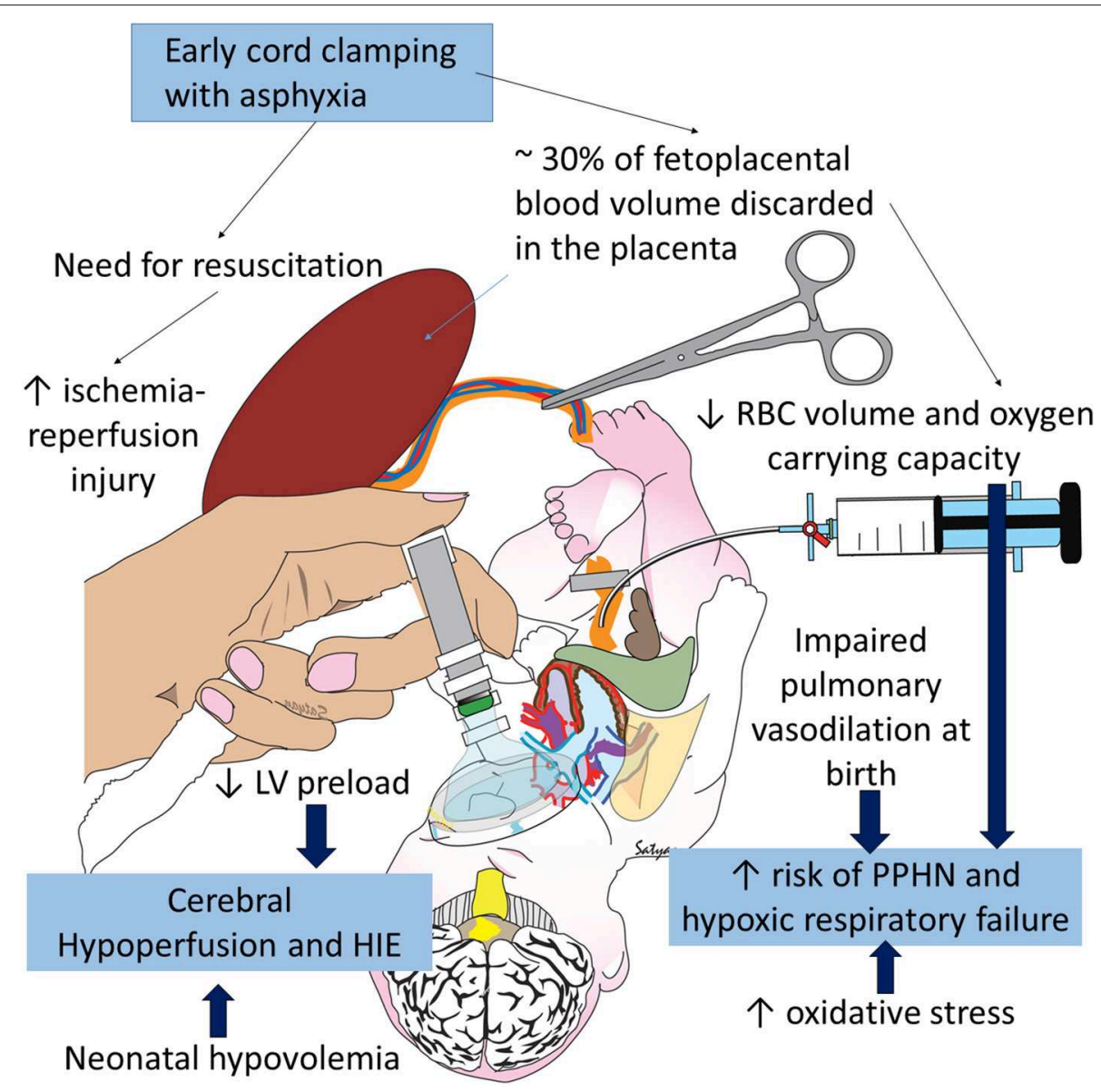

FIGURE 3 | Negative consequences of early cord clamping in asphyxia: asphyxia increases the need for resuscitation and is associated with hypoxic-ischemic encephalopathy (HIE) and persistent pulmonary hypertension of the newborn (PPHN). Early cord clamping reduces blood and RBC volume in the neonate and increases fetal blood left in the placenta. Hypovolemia and hypoxia contribute to cerebral hypoperfusion and HIE and exacerbate pulmonary hypoperfusion and PPHN. Studies have shown increased oxidative stress with early cord clamping compared to delayed cord clamping and umbilical cord milking. Oxidative stress contributes to HIE and PPHN. Copyright Satyan Lakshminrusimha, MD.

ischemia (27). In older physiologic studies comparing UCM or DCC with ECC, ECC resulted in less favorable outcomes in non-asphyxiated infants including: hypovolemia, lower blood pressures, increased vascular resistance, decreased red cell volume, less flow to brain, intestines and kidneys, lower urine output, increased sodium excretion, and lower red cell volume, hematocrit, and hemoglobin levels (28-33). These findings need confirmation in clinical trials that include asphyxiated infants.

Using the Iodine serum albumin method, Yao et al. preformed an elegant blood dilation experiment in 111 full term deliveries (26). The infants were divided into groups based on the time the umbilical cord was clamped. Combining the dilution method with placental residual blood volume (draining the placenta while it was still in utero and after delivery), they found that the proportion of the total fetoplacental blood volume that is in the infant/placenta was $67 / 33$ percent at birth, $80 / 20$ at $1 \mathrm{~min}$ at $87 / 13$ at the end of the placental transfusion (about $3 \mathrm{~min}$ ).

Lindercamp et al. looked at blood volume in 194 newborn infants (26-41 weeks) that received ECC (clamping before $15 \mathrm{~s}$ following vaginal birth and $5 \mathrm{~s}$ after Cesarean section delivery) (34). There were no differences in blood volume based on gestational age or mode of delivery (Table 1). Vaginal delivered infants with a $1 \mathrm{~min}$ Apgar score of $\leq 5$ had a lower blood and $\mathrm{RBC}$ volume compared to infants with a $1 \mathrm{~min}$ Apgar score of $>5$. Infants with intrauterine asphyxia had much higher blood volumes (90 vs. $78 \mathrm{ml} / \mathrm{kg}$ ). We speculate that infants with intrauterine asphyxia may receive a marked placental transfusion in utero. This may be due to the loss of systemic vasomotor response resulting in lower fetal blood pressure compared to the placenta, gasping respirations, or erythropoiesis due to chronic compromise. In sharp contrast, intrapartum asphyxia with a tight

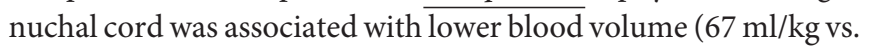
$78 \mathrm{ml} / \mathrm{kg}$ ). These results suggest that infants with intra-partum asphyxia and/or tight nuchal cords have hypovolemia (Figure 1) and may lose some blood back to the placenta. We conclude that hypovolemia is common with intrapartum asphyxia and placental transfusion may improve or restore cardiac output and systemic circulation. 
TABLE 1 | Changes in neonatal blood volume and RBC volume based on mode of delivery and complications.

\begin{tabular}{|c|c|c|c|c|}
\hline Mode of delivery & Event & $\begin{array}{l}\text { Apgar } \\
\text { score }\end{array}$ & $\begin{array}{l}\text { Blood volume } \\
\text { (ml/kg) }\end{array}$ & $\begin{array}{l}\text { RBC volume } \\
(\mathrm{ml} / \mathrm{kg})\end{array}$ \\
\hline Vaginal delivery (15s & No & Apgar $>5$ & $77.9 \pm 6.2$ & $37.5 \pm 5.1$ \\
\hline clamp, $n=141$ ) & $\begin{array}{l}\text { complications } \\
(n=96)\end{array}$ & Apgar $\leq 5$ & $70 \pm 4.4^{\star}$ & $29.6 \pm 2.9^{\star}$ \\
\hline $\begin{array}{l}\text { C-section (5s } \\
\text { clamp, } n=53)\end{array}$ & $\begin{array}{l}\text { No } \\
\text { complications } \\
(n=25)\end{array}$ & $\begin{array}{l}\text { No effect } \\
\text { of Apgar }\end{array}$ & $71.3 \pm 4.8^{\star}$ & $31.2 \pm 3.6^{\star}$ \\
\hline $\begin{array}{l}\text { Intrauterine asphyxia } \\
(n=56)\end{array}$ & & & $90.4 \pm 7.0^{\dagger}$ & $46.9 \pm 6.3^{\dagger}$ \\
\hline $\begin{array}{l}\text { Intrapartum } \\
\text { asphyxia Tight } \\
\text { nuchal cord }(n=17)\end{array}$ & & & $67.5 \pm 5.7^{\star}$ & $27.4 \pm 2.7^{\star}$ \\
\hline
\end{tabular}

Significantly lower ${ }^{\star}$ or higher ${ }^{\dagger}$ than vaginal delivery with Apgar > 5; data from Linderkamp et al. (35).

\section{BREATHING AND PLACENTAL TRANSFUSION (FIGURE 4)}

A large observational study reported that newborns were more likely to be admitted to the NICU or die if their cord was clamped before they started to breathe (36). Recent data from animal studies suggests that clamping the cord before the onset of breathing leads to decreases in heart rate, right ventricular output, and pulmonary blood flow, while causing a transient spike in carotid artery blood flow (37). ECC leads to an increase in afterload and a decrease in preload, which in turn causes a significant reduction in cardiac output. Compared to UCM, preterm infants receiving ECC at birth had lower heart rates and oxygen saturation and required more oxygen and ventilation within the first $5 \mathrm{~min}$ of life (20). These findings highlight impaired transition from ECC in the presence of lung expansion, which likely contributed to the downstream morbidities such as increased early hypotension, number of days on oxygen, and chronic lung disease seen in the ECC group compared to UCM (38).

Optimal functioning of the left ventricle is key to normal transition at birth. Establishing ventilation of the lungs when placental circulation is still intact offers several advantages. The left ventricular afterload is low due to the presence of lowresistance umbilical circulation (Figure 4). The left ventricular preload is optimized due to dual sources of blood: umbilical venous return and pulmonary venous return (37). In addition, Davidson et al. have made some preliminary observations that diastolic pressures (an important determinant of coronary perfusion) are higher in asphyxiated lambs resuscitated with an intact cord (39).

\section{ASPHYXIA, OXIDATIVE STRESS, AND PPHN}

Infants exposed to perinatal distress and birth asphyxia are at high risk of developing HIE and persistent pulmonary hypertension of the newborn (PPHN) (40). Oxidative and nitrosative stress play an important role in pathogenesis of PPHN and HIE (41). Intrapartum placental transfusion increases oxygen carrying capacity of blood and some preliminary data suggest that $\mathrm{PPHN}$ is associated with lower hemoglobin levels (42). A study comparing RBC catalase activity, superoxide dismutase (SOD), and total antioxidant status between ECC and DCC suggested that delayed clamping increases antioxidant capacity and reduces inflammatory effects during delivery and exerts beneficial effects on the neonate (43). DCC is also shown to increase plasma thiol levels and decrease disulfide levels in umbilical arterial blood suggesting reduced oxidative stress (44). Total antioxidant activity, RBC catalase cytosol, SOD cytosol and glutathione perioxidase cytosol are all higher with DCC along with reduced plasma hydroperioxide levels (45). DCC is being investigated in a pilot trial for infants born with congenital diaphragmatic hernia $(\mathrm{CDH})$, a common cause of intractable PPHN (NCT03314233). Studies in lambs suggest that physiological/DCC reduces pulmonary vascular resistance (PVR) and significantly increases pulmonary blood flow in $\mathrm{CDH}$ (46). A strategy combining ventilation with lower levels of inspired oxygen $(47,48)$ with an intact cord might be an effective approach during the delivery room resuscitation of $\mathrm{CDH}$ (Figure 5).

\section{ANIMAL DATA TO DATE}

The appropriateness of animal models for placental transfusion is not clear. Most of the current research involves ovine models. All of the animal models are also delivered only by Cesarean Section. Many ovine models do not use antenatal steroids which do alter the cardiopulmonary mechanics at birth following preterm delivery. The placenta in lambs is cotyledonary and the umbilical cord is relatively short. Majority of these studies are performed with an atonic uterus with a cesarean section. However, these studies provide valuable physiological data on cardiopulmonary interactions during ventilation with an intact cord.

Term lambs with asphyxia, bradycardia, and hypotension resuscitated with an intact cord demonstrated more stable cerebral perfusion and reduced cerebrovascular injury as indicated by reduced expression of blood-brain barrier protein leakage in the subcortical white matter and gray matter (49). The authors have advocated for physiologic based cord clamping, which suggests to clamp the cord when the infant has maintained stable respirations. Whether asphyxiated infants will be able to achieve stable respirations is unclear and needs to be tested prospectively in a randomized controlled trial.

The effect of PPV on placental transfusion has been evaluated in lambs. Creasy et al. did not observe an increase in neonatal blood volume following PPV with an intact cord in lambs (50). Bhatt et al. reported stable hemodynamic transition when PPV was initiated prior to cord clamping in lambs (37).

The effect of spontaneous respiration on placental transfusion is unclear. It was traditionally thought that the negative intrathoracic pressure generated by spontaneous respirations, in addition to gravity and uterine contractions, contributed to the pressure gradient from the placenta to the neonatal circulation $(6,51,52)$. More recent studies in preterm lambs suggest that diaphragmatic contractions during spontaneous inspiration may 


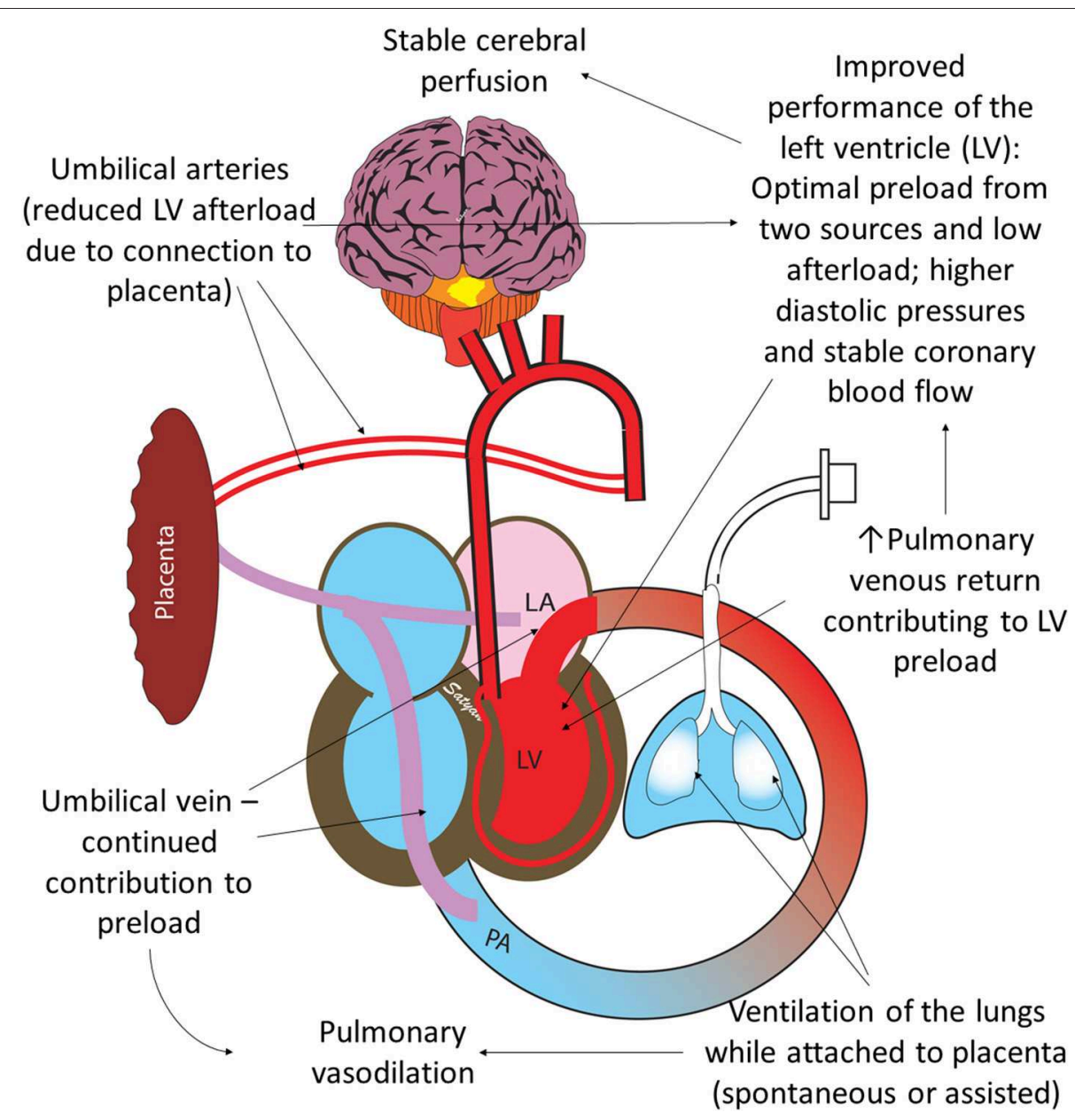

FIGURE 4 | Benefits of ventilation of the lungs with an intact umbilical cord: optimal performance of the left ventricle (LV) is important for hemodynamic transition at birth. Umbilical venous return from the placenta and pulmonary venous return both contribute to LV preload. Ventilation of the lung leads to pulmonary vasodilation and increases pulmonary venous return. Umbilical arteries perfusing the placenta maintain low LV afterload. High diastolic pressure due to higher RBC volume following placental transfusion leads to better coronary perfusion. Copyright Satyan Lakshminrusimha, MD.

compress the inferior vena cava and inhibit umbilical venous flow (53).

UCM with or without placental refill has not been shown to be beneficial in preterm lambs. Blank et al. observed significant hemodynamic disturbance with UCM in preterm lambs (54). Preliminary data by Chandrasekharan et al. suggest that fluctuations in carotid and pulmonary blood flow are common in preterm lambs without respirations receiving UCM (55). Interestingly, PPV during milking reduced fluctuations in carotid and pulmonary flow (Figure 6). Further evaluation of hemodynamic effects of milking in preterm animal models is warranted.

\section{CLINICAL TRIALS TO DATE}

\section{Resuscitation With an Intact Cord}

There are several large ongoing trials evaluating resuscitation with an intact cord to allow for a placental transfusion in a potentially asphyxiated population. Other trials that have included resuscitation on the cord but did not specifically target non-breathing or depressed infants are not discussed here.

\section{Term Infants}

Andersson et al. have completed a large RCT in non-breathing term infants comparing DCC with resuscitation (up to $180 \mathrm{~s}$ ) to ECC of $<60 \mathrm{~s}$. They demonstrated improved Apgar scores and $\mathrm{SpO}_{2} 10 \mathrm{~min}$ after birth (56). Blank et al. have an ongoing trial (Blank et al., ongoing trial, Baby DUCC, Australian New Zealand trial registry Identifier: AZTN1261800621213) randomizing nonbreathing infants to immediate cord clamping $(<10 \mathrm{~s})$ or DCC with resuscitation until they have achieved 1 min of gas exchange via a colorimetric carbon dioxide detector in the first 5 min of life.

\section{Preterm Infants}

Nevill et al. have an ongoing trial to randomize preterm infants not breathing well by $15 \mathrm{~s}$ of life and randomizing them to receive CPAP and or positive pressure ventilation or stimulation alone 


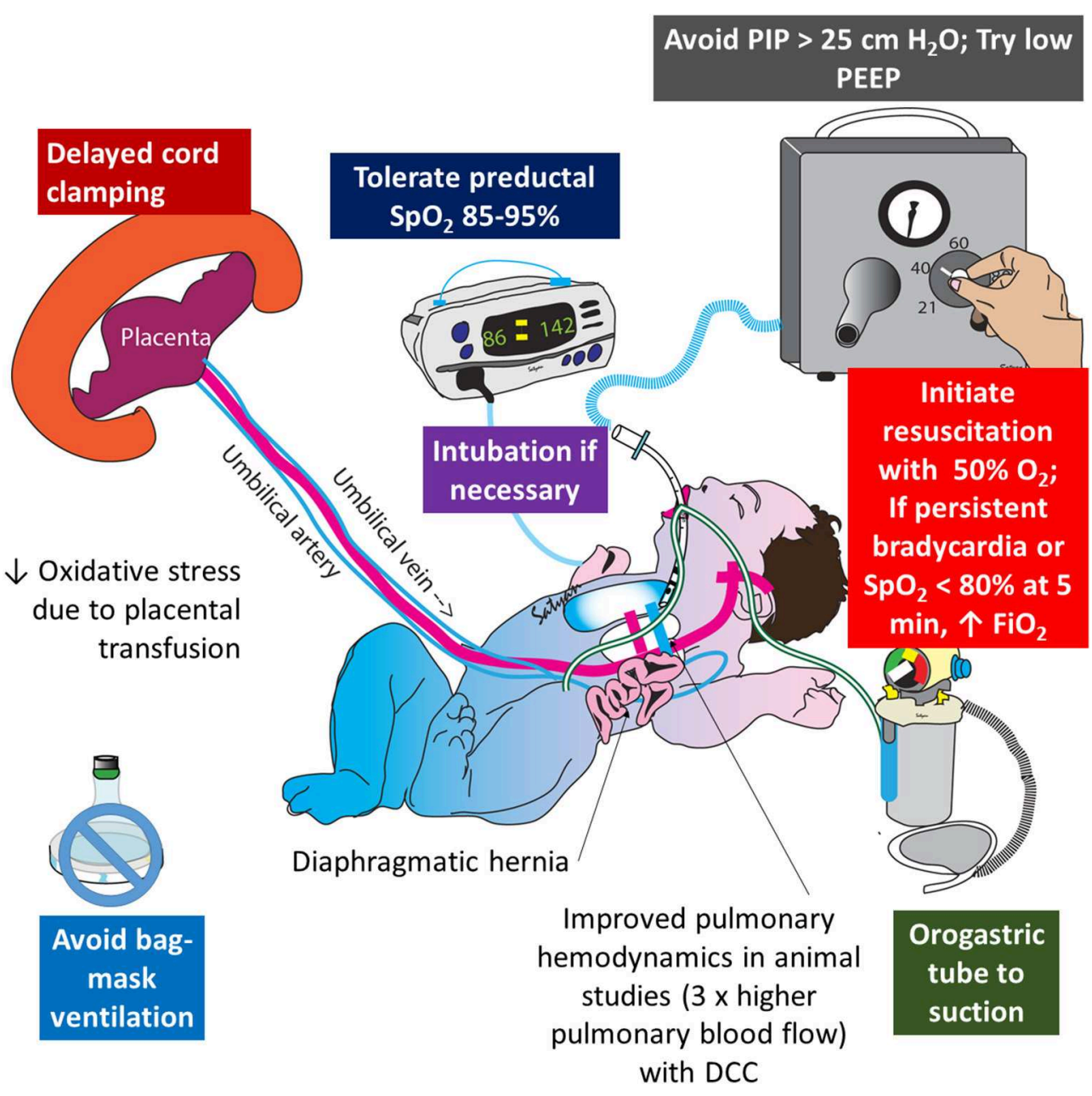

FIGURE 5 | Role of delayed cord clamping in congenital diaphragmatic hernia (CDH): oxidative stress plays an important role in the pathogenesis of pulmonary hypertension and injury to hypoplastic lungs in $\mathrm{CDH}$. Delayed cord clamping, limiting barotrauma (with low ventilator pressures), restricting $\mathrm{FiO}_{2}$ to target preductal $\mathrm{SpO}_{2}$ in the mid-80s to low 90s are important strategies to limit oxidative stress in CDH. Copyright Satyan Lakshminrusimha, MD.

during DCC. Both arms will have cord clamping by $60 \mathrm{~s}$ of life (Nevill et al. ongoing trial, ABC trial, Australian New Zealand trial registry Identifier: AZTN12615001026516).

\section{Feasibility Issues With Resuscitation With an Intact Cord}

Our group has experience with conducting two trials of resuscitation with an intact cord in a term and preterm population (57, 58). For the preterm infant, most of the challenges were overcome with having adequate time to prepare for the delivery and setup the equipment. The majority of preterm infants are born by Cesarean Section; and keeping specialized cord clamping resuscitation trolley near the operating room made this feasible. There were issues regarding adequate spacing for personnel to help with the resuscitation (i.e., changing pressures during PPV), and the lack of sterile EKG leads and pulse oximetry probes to provide monitoring. For a $60 \mathrm{~s}$ delay in cord clamping this could be appropriate but the ongoing studies will need to include additional monitoring and personnel.
The changes are necessary in order to be in line with current resuscitation guidelines which mandate adequate monitoring in infants that need resuscitation.

The most challenging population to perform resuscitation on the cord is the term asphyxiated infant. These infants do not present with enough warning since the majority of at risk term deliveries do not need resuscitation. In our pilot trial of resuscitation with an intact cord in term infants and found less than a quarter required any resuscitation (57). Our survey found resuscitation with an intact cord was challenging (59). Spacing in front of the mother during delivery with an obstetrical provider and the placement of monitoring devices was cumbersome. Further work on equipment and personnel optimization and determination whether they need to be placed in every Labor and Delivery room must occur before this method can be standard practice. The cost of these beds may be prohibitive in many countries. A low-tech option is being developed and tested in Uganda (https://www.thebabysaver.org/ about-the-babysaver/) and may be an alternative. 


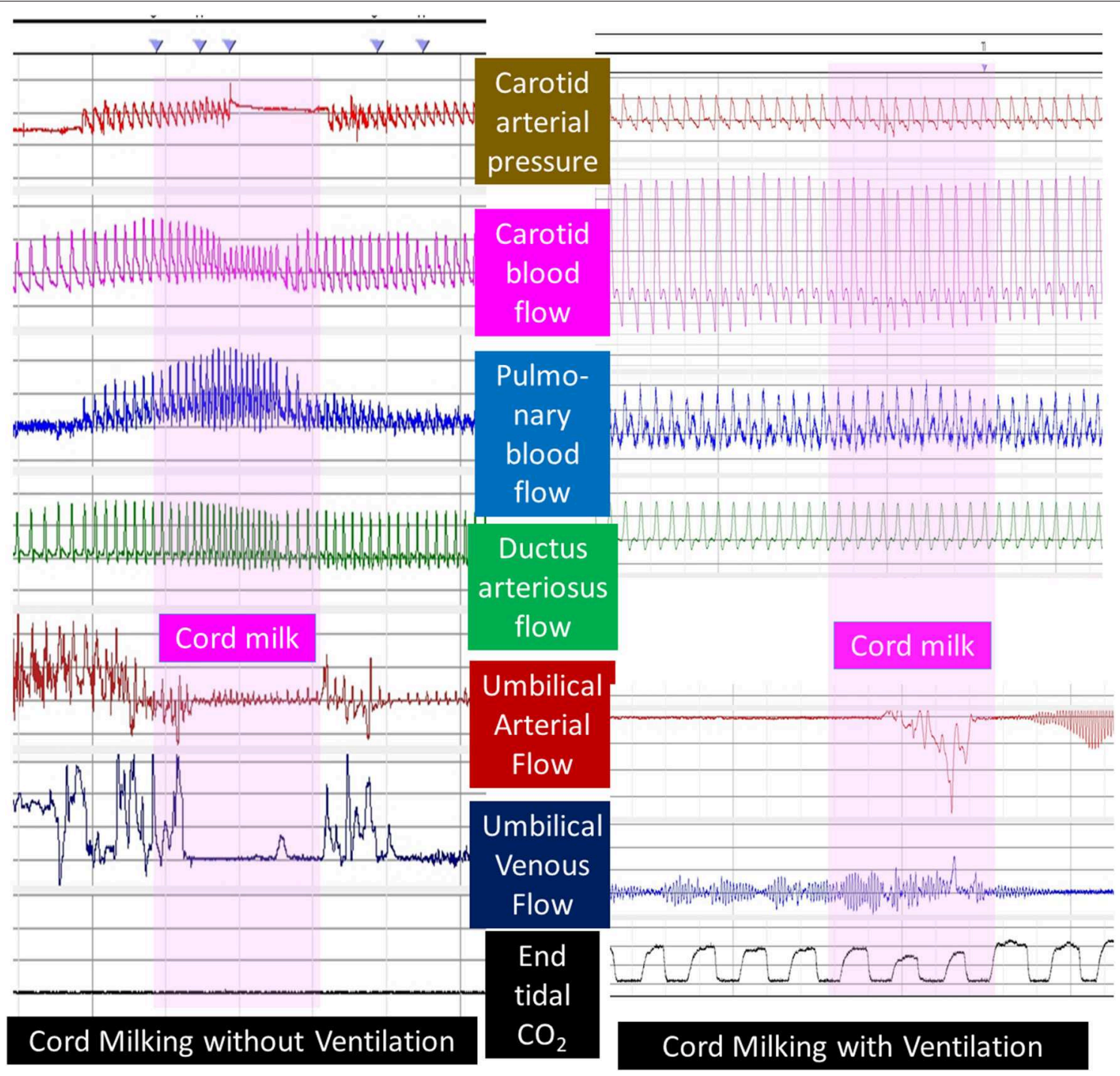

FIGURE 6 | Umbilical cord milking and carotid and pulmonary hemodynamics in preterm lambs: a graph showing carotid arterial pressure, left carotid blood flow, left pulmonary arterial flow, ductus arteriosus flow, umbilical arterial, and venous flow and end-tidal $\mathrm{CO}_{2}$ in preterm lambs undergoing umbilical cord milking (pink vertical bar) without or with simultaneous ventilation of the lungs. Units are shown to the left and right of the figure. Interestingly, umbilical arteries went into spasm after initiation of PPV and did not demonstrate pulsatile flow. Courtesy/Copyright Praveen Chandrasekharan MD (with permission).

\section{Cord Milking}

An alternative to DCC with resuscitation is UCM. There are two methods to perform UCM. Intact cord milking (I-UCM) is performed by grasping the unclamped umbilical cord the blood is pushed ("stripped") toward the infant two to four times before it is clamped. Cut cord milking (C-UCM) involves clamping and cutting a long segment of the umbilical cord immediately after birth and passing the baby and the long cord to the pediatrics provider. Both methods can be performed in about $20 \mathrm{~s}$ allowing resuscitation to take place quickly. Intact cord milking has been shown to increase the incidence of severe IVH in extremely preterm infants ( $<28$ weeks) in a recently presented abstract (Katheria et al., ongoing trial, Premature Infants Receiving Milking or Delayed Cord Clamping:
PREMOD2. ClinicalTrials.gov Identifier: NCT03019367). While there are several trials of both I-UCM and C-UCM, only studies evaluating depressed newborns will be discussed here.

\section{Preterm Infants}

To date, there is one small trial evaluating UCM in depressed infants. Ram Mohan et al. randomized 60 preterm infants that required resuscitation to either C-UCM or ECC. There were no differences in clinical outcomes but C-UCM infant showed higher hemoglobin and ferritin levels at 6 weeks of life (60).

\section{Term Infants}

There is only one trial that has evaluated UCM in depressed term infants. Girish et al. quasi-randomized (alternating months) 
101 infants to either I-UCM or ECC in depressed newborns unable to receive DCC (61). There were no clinical differences in outcomes. There is one ongoing large multicenter trial (Katheria et al., ongoing trial, Milking in Non-Vigorous Infants, ClinicalTrials.org Identifier: NCT03631940) to evaluate the short and long term benefits of I-UCM in non-vigorous near term and term newborns compared to ECC.

\section{CONCLUSIONS}

While delivery of a depressed newborn presents the challenges of a high-pressure environment, ensuring an adequate placental transfusion for these infants may be

\section{REFERENCES}

1. Conway JM, Walsh BH, Boylan GB, Murray DM. Mild hypoxic ischaemic encephalopathy and long term neurodevelopmental outcome - A systematic review. Early Hum Dev. (2018) 120:80-7. doi: 10.1016/j.earlhumdev.2018.02.007

2. Perez A, Ritter S, Brotschi B, Werner H, Caflisch J, Martin E, et al. Longterm neurodevelopmental outcome with hypoxic-ischemic encephalopathy. J Pediatr. (2013) 163:454-9. doi: 10.1016/j.jpeds.2013.02.003

3. Martinez-Biarge M, Cheong JL, Diez-Sebastian J, Mercuri E, Dubowitz LM, Cowan FM. Risk factors for neonatal arterial ischemic stroke: the importance of the intrapartum period. J Pediatr. (2016) 173:62-8.e1. doi: 10.1016/j.jpeds.2016.02.064

4. Getahun D, Rhoads GG, Demissie K, Lu SE, Quinn VP, Fassett MJ, et al. In utero exposure to ischemic-hypoxic conditions and attention-deficit/hyperactivity disorder. Pediatrics. (2013) 131:e53-61. doi: 10.1542/peds.2012-1298

5. Zhu T, Gan J, Huang J, Li Y, Qu Y, Mu D. Association between perinatal hypoxic-ischemic conditions and attention-deficit/hyperactivity disorder: a meta-analysis. J Child Neurol. (2016) 31:1235-44. doi: $10.1177 / 0883073816650039$

6. Yao AC, Lind J. Blood flow in the umbilical vessels during the third stage of labor. Biol Neonate. (1974) 25:186-93. doi: 10.1159/000240691

7. Mercer J, Erickson-Owens D, Skovgaard R. Cardiac asystole at birth: is hypovolemic shock the cause? Med Hypotheses. (2009) 72:458-63. doi: 10.1016/j.mehy.2008.11.019

8. Menticoglou S, Schneider C. Resuscitating the baby after shoulder dystocia. (2016) 2016:8674167. doi: 10.1155/2016/8674167

9. Aladangady N, McHugh S, Aitchison TC, Wardrop CA, Holland BM. Infants' blood volume in a controlled trial of placental transfusion at preterm delivery. Pediatrics. (2006) 117:93-8. doi: 10.1542/peds.2004-1773

10. Strauss RG, Mock DM, Johnson K, Mock NI, Cress G, Knosp L, et al. Circulating RBC volume, measured with biotinylated RBCs, is superior to the Hct to document the hematologic effects of delayed versus immediate umbilical cord clamping in preterm neonates. Transfusion. (2003) 43:1168-72. doi: 10.1046/j.1537-2995.2003.00454.x

11. McDonald SJ, Middleton P, Dowswell T, Morris PS. Effect of timing of umbilical cord clamping of term infants on maternal and neonatal outcomes. Evid Based Child Health. (2014) 9:303-97. doi: 10.1002/ebch.1971

12. American Academy of Pediatrics and American Heart Association. Textbook of Neonatal Resuscitation, 7th ed. Elk Grove Village, IL. (2016).

13. Arcilla RA, Oh W, Lind J, Gessner IH. Pulmonary arterial pressures of newborn infants born with early and late clamping of the cord. Acta Paediatr Scand. (1966) 55:305-15. doi: 10.1111/j.1651-2227.1966.tb17659.x

14. Colozzi AE. Clamping of the umbilical cord; its effect on the placental transfusion. N Engl J Med. (1954) 250:629-32. doi: 10.1056/NEJM195404152501502 the first and most important step in ensuring the best possible outcome. Several aspects of pathophysiology of HIE and PPHN following birth asphyxia could potentially be mitigated by avoidance of ECC. The benefit of placental transfusion in such high-risk patients requires further study.

\section{AUTHOR CONTRIBUTIONS}

AK developed and wrote the first version of the manuscript. SB and WR revised and edited the manuscript. SL contributed animal data, new clinical studies, drew figures, and edited the manuscript.

15. Walsh SZ. Early clamping versus stripping of card: comparative study of electrocardiogram in neonatal period. Br Heart J. (1969) 31:122-6. doi: 10.1136/hrt.31.1.122

16. Erickson-Owens DA, Mercer JS, Oh W. Umbilical cord milking in term infants delivered by cesarean section: a randomized controlled trial. $J$ Perinatol. (2012) 32:580-4. doi: 10.1038/jp.2011.159

17. Upadhyay A, Gothwal S, Parihar R, Garg A, Gupta A, Chawla D, et al. Effect of umbilical cord milking in term and near term infants: randomized control trial. Am J Obstet Gynecol. (2013) 208:120.e1-6. doi: 10.1016/j.ajog.2012.10.884

18. Jaiswal P, Upadhyay A, Gothwal S, Chaudhary H, Tandon A. Comparison of umbilical cord milking and delayed cord clamping on cerebral blood flow in term neonates. Indian J Pediatr. (2015) 82:890-5. doi: 10.1007/s12098-015-1734-2

19. Al-Wassia H, Shah PS. Efficacy and safety of umbilical cord milking at birth: a systematic review and meta-analysis. JAMA Pediatr. (2015) 169:18-25. doi: 10.1001/jamapediatrics.2014.1906

20. Katheria A, Blank D, Rich W, Finer N. Umbilical cord milking improves transition in premature infants at birth. PLoS ONE. (2014) 9:e94085. doi: 10.1371/journal.pone. 0094085

21. Hosono S, Mugishima H, Fujita H, Hosono A, Minato M, Okada T, et al. Umbilical cord milking reduces the need for red cell transfusions and improves neonatal adaptation in infants born at less than 29 weeks' gestation: a randomised controlled trial. Arch Dis Child Fetal Neonatal Ed. (2008) 93:F14-9. doi: 10.1136/adc.2006.108902

22. Mercer JS, Erickson-Owens DA. Rethinking placental transfusion and cord clamping issues. J Perinat Neonatal Nurs. (2012) 26:202-17; quiz 218-9. doi: 10.1097/JPN.0b013e31825d2d9a

23. Rich W, Finer NN, Gantz MG, Newman NS, Hensman AM, Hale EC, et al. Enrollment of extremely low birth weight infants in a clinical research study may not be representative. Pediatrics. (2012) 129:480-4. doi: 10.1542/peds.2011-2121

24. Rich WD, Leone T, Finer NN. Delivery room intervention: improving the outcome. Clin Perinatol. (2010) 37:189-202. doi: 10.1016/j.clp.2010.01.011

25. Committee on Obstetric Practice. Committee Opinion No. 684: delayed umbilical cord clamping after birth. Obstet Gynecol. (2017) 129:e5-e10. doi: 10.1097/AOG.0000000000001860

26. Yao AC, Moinian M, Lind J. Distribution of blood between infant and placenta after birth. Lancet. (1969) 2:871-3. doi: 10.1016/S0140-6736(69)92328-9

27. Rajnik M, Salkowski CA, Thomas KE, Li YY, Rollwagen FM, Vogel SN Induction of early inflammatory gene expression in a murine model of nonresuscitated, fixed-volume hemorrhage. Shock. (2002) 17:322-8. doi: 10.1097/00024382-200204000-00015

28. Nelle M, Zilow EP, Kraus M, Bastert G, Linderkamp O. The effect of Leboyer delivery on blood viscosity and other hemorheologic parameters in term neonates. Am J Obstet Gynecol. (1993) 169:189-93. doi: 10.1016/0002-9378(93)90161-B 
29. Oh W, Lind J. Venous and capillary hematocrit in newborn infants and placental transfusion. Acta Pcediatrica. (1966) 55:38-48. doi: 10.1111/j.1651-2227.1966.tb15207.x

30. Oh W, Oh MA, Lind J. Renal function and blood volume in newborn infant related to placental transfusion. Acta Pcediatrica. (1966) 55:197-210. doi: 10.1111/j.1651-2227.1966.tb15226.x

31. Oh W, Fanaroff AA, Carlo WA, Donovan EF, McDonald SA, Poole WK. Eunice kennedy shriver national institute of child health and human development neonatal research network. J Perinatol. (2011) 51 (Suppl. 31) doi: 10.1038/jp.2010.186.

32. Nelle M, Fisher S, Conze S, Beedgen B, Grischke EM, Linderkamp O. Effects of later cord clamping on circulation in prematures (Abstract). Pediatr Res. (1998) 44:420. doi: 10.1203/00006450-199809000-00245

33. Nelle M, Zilow EP, Bastert G, Linderkamp O. Effect of Leboyer childbirth on cardiac output, cerebral and gastrointestinal blood flow velocities in full-term neonates. Am J Perinatol. (1995) 12:212-6. doi: 10.1055/s-2007-994455

34. Linderkamp O. Placental transfusion: determinants and effects. Clin Perinatol. (1982) 9:559-92. doi: 10.1016/S0095-5108(18)31013-3

35. Linderkamp O, Versmold HT, Messow-Zahn K, Müller-Holve W, Riegel KP, Betke K. The effect of intra-partum and intrauterine asphyxia on placental transfusion in premature and full-term infants. Eur J Pediatr. (1978) 127:91-9.

36. Ersdal HL, Linde J, Mduma E, Auestad B, Perlman J. Neonatal outcome following cord clamping after onset of spontaneous respiration. Pediatrics. (2014) 134:265-72. doi: 10.1542/peds.2014-0467

37. Bhatt S, Alison BJ, Wallace EM, Crossley KJ, Gill AW, Kluckow M, et al. Delaying cord clamping until ventilation onset improves cardiovascular function at birth in preterm lambs. J Physiol. (2013) 591 (Pt 8):2113-26. doi: 10.1113/jphysiol.2012.250084

38. Katheria AC, Leone TA, Woelkers D, Garey DM, Rich W, Finer NN. The effects of umbilical cord milking on hemodynamics and neonatal outcomes in premature neonates. J Pediatr. (2014) 164:1045-50.e1. doi: 10.1016/j.jpeds.2014.01.024

39. Davidson LLS, Gugino S, Koenigsknecht C, Helman J, Nair J. Resuscitation with delayed cord clamping in asystolic term lambs. Pediatr Acad Soc. (2017). 1563.3

40. Lapointe A, Barrington KJ. Pulmonary hypertension and the asphyxiated newborn. J Pediatr. (2011) 158 (Suppl. 2):e19-24. doi: $10.1016 /$ j.jpeds.2010.11.008

41. Wedgwood S, Steinhorn RH, Lakshminrusimha S. Optimal oxygenation and role of free radicals in PPHN. Free Radic Biol Med. (2019) 142:97-106. doi: 10.1016/j.freeradbiomed.2019.04.001

42. Totapally B, Raju N, Perlman M. Decreased placental transfusion may lead to persistent pulmonary hypertension of the newborn (PPHN) - abstract PAS. Pediatr Res. (1998) 43:198. doi: 10.1203/00006450-199804001-01177

43. Díaz-Castro J, Florido J, Kajarabille N, Garrido-Sánchez M, Padilla C, de Paco $\mathrm{C}$, et al. The timing of cord clamping and oxidative stress in term newborns. Pediatrics. (2014) 134:257-64. doi: 10.1542/peds.2013-3798

44. Vatansever B, Demirel G, Ciler Eren E, Erel O, Neselioglu S, Karavar HN, et al. Is early cord clamping, delayed cord clamping or cord milking best? J Matern Fetal Neonatal Med. (2018) 31:877-80. doi: 10.1080/14767058.2017.1300647

45. Moustafa AN, Ibrahim MH, Mousa SO, Hassan EE, Mohamed HF, Moness HM. Association between oxidative stress and cord serum lipids in relation to delayed cord clamping in term neonates. Lipids Health Dis. (2017) 16:210. doi: 10.1186/s12944-017-0599-y

46. Kashyap AJ, Dekoninck PLJ, Rodgers KA, Thio M, Mcgillick EV, Amberg BJ, et al. Antenatal sildenafil treatment improves neonatal pulmonary hemodynamics and gas exchange in lambs with diaphragmatic hernia. Ultrasound Obstet Gynecol. (2019) 54:506-16. doi: 10.1002/uog. 20415

47. Riley JS, Antiel RM, Rintoul NE, Ades AM, Waqar LN, Lin N, et al. Reduced oxygen concentration for the resuscitation of infants with congenital diaphragmatic hernia. J Perinatol. (2018) 38:834-43. doi: 10.1038/s41372-017-0031-5
48. Lakshminrusimha S, Swartz DD, Gugino SF, Ma CX, Wynn KA, Ryan $\mathrm{RM}$, et al. Oxygen concentration and pulmonary hemodynamics in newborn lambs with pulmonary hypertension. Pediatr Res. (2009) 66:539-44. doi: 10.1203/PDR.0b013e3181bab0c7

49. Polglase GR, Blank DA, Barton SK, Miller SL, Stojanovska V, Kluckow M, et al. Physiologically based cord clamping stabilises cardiac output and reduces cerebrovascular injury in asphyxiated near-term lambs. Arch Dis Child Fetal Neonatal Ed. (2018) 103:F530-f538. doi: 10.1136/archdischild-2017-313657

50. Creasy RK, Drost M, Green MV, Morris JA. Effect of ventilation on transfer of blood from placenta to neonate. Am J Physiol. (1972) 222:186-8. doi: 10.1152/ajplegacy.1972.222.1.186

51. Nyberg MK, Johnsen SL, Rasmussen S, Kiserud T. Hemodynamics of fetal breathing movements: the inferior vena cava. Ultrasound Obstet Gynecol. (2011) 38:658-64. doi: 10.1002/uog.9000

52. Katheria A. Optimizing care of the preterm infant starting in the delivery room. Minerva Pediatr. (2016) 33:297-304. doi: 10.1055/s-00351570385

53. Brouwer E, Te Pas AB, Polglase GR, McGillick EV, Böhringer S, Crossley KJ, et al. Effect of spontaneous breathing on umbilical venous blood flow and during delayed cord clamping in preterm lambs. Arch Dis Child Fetal Neonatal Ed. (2019). doi: 10.1136/archdischild-2018-316044. [Epub ahead of print].

54. Blank DA, Badurdeen S, Omar F Kamlin C, Jacobs SE, Thio M, Dawson JA, et al. Baby-directed umbilical cord clamping: a feasibility study. Resuscitation. (2018) 131:1-7. doi: 10.1016/j.resuscitation.2018. 07.020

55. Chandrasekharan P, Gugino S, Koenigsknecht C, Helman J, Rawat M, Nair J, et al. Placental transfusion during resuscitation of a partially asphyxiated preterm model. In: Pediatric Academic Society Meeting. (2018) 1725.4.

56. Andersson O, Rana N, Ewald U, Målqvist M, Stripple G, Basnet O, et al. Intact cord resuscitation versus early cord clamping in the treatment of depressed newborn infants during the first 10 minutes of birth (Nepcord III) - a randomized clinical trial. Matern Health Neonatol Perinatol. (2019) 5:15. doi: 10.1186/s40748-019-0110-z

57. Katheria AC, Brown MK, Faksh A, Hassen KO, Rich W, Lazarus D, et al. Delayed cord clamping in newborns born at term at risk for resuscitation: a feasibility randomized clinical trial. J Pediatr. (2017) 187:313-7.e1. doi: 10.1016/j.jpeds.2017.04.033

58. Katheria A, Poeltler D, Durham J, Steen J, Rich W, Arnell K, et al. Neonatal resuscitation with an intact cord: a randomized clinical trial. J Pediatr. (2016) 178:75-80.e3. doi: 10.1016/j.jpeds.2016.07.053

59. Katheria AC, Sorkhi SR, Hassen K, Faksh A, Ghorishi Z, Poeltler D. Acceptability of bedside resuscitation with intact umbilical cord to clinicians and patients' families in the United States. Front Pediatr. (2018) 6:100. doi: $10.3389 /$ fped.2018.00100

60. Ram Mohan G, Shashidhar A, Chandrakala BS, Nesargi S, Suman Rao PN, Ram Mohan G, et al. Umbilical cord milking in preterm neonates requiring resuscitation: a randomized controlled trial. Resuscitation. (2018) 130:88-91. doi: 10.1016/j.resuscitation.2018.07.003

61. Girish M, Jain V, Dhokane R, Gondhali SB, Vaidya A, Aghai ZH. Umbilical cord milking for neonates who are depressed at birth: a randomized trial of feasibility. J Perinatol. (2018) 38:1190-6. doi: 10.1038/s41372-018-0161-4

Conflict of Interest: The authors declare that the research was conducted in the absence of any commercial or financial relationships that could be construed as a potential conflict of interest.

Copyright (c) 2019 Katheria, Rich, Bava and Lakshminrusimha. This is an openaccess article distributed under the terms of the Creative Commons Attribution License (CC BY). The use, distribution or reproduction in other forums is permitted, provided the original author(s) and the copyright owner(s) are credited and that the original publication in this journal is cited, in accordance with accepted academic practice. No use, distribution or reproduction is permitted which does not comply with these terms. 